\title{
Genotyping Gastric Cancer: Reply
}

\author{
Hakan Alakus · Stefan P. Mönig
}

Published online: 3 May 2011

(c) Société Internationale de Chirurgie 2011

We thank Dr. Spiliotis [1] very much for his comment on our article [2]. Several studies have shown that single nucleotide polymorphisms (SNPs) seem to play a major role as risk factors for and as prognostic molecular markers in gastric cancer. Certainly it would be unrealistic to believe that SNPs alone effect carcinogenesis and cancer progression. Our study is now part of the discussion about whether SNPs have any influence in gastric cancer, especially since it contradicts previous findings with fewer samples. We agree that the development of further highthroughput techniques and new sequencing technologies will gain in importance for more personalized medicine. It is just a matter of time when these new techniques of whole-genome sequencing will be used in the daily clinic routine for gastric cancer.

\section{References}

1. Spiliotis J (2011) Genotyping gastric cancer. World J Surg 35. doi:10.1007/s00268-011-1005-y

2. Alakus H, Afriani N, Warnecke-Eberz U et al (2010) Clinical impact of MMP and TIMP gene polymorphisms in gastric cancer. World J Surg 34:2853-2859
H. Alakus $(\bowtie) \cdot$ S. P. Mönig

Department of General, Visceral and Cancer Surgery, University

of Cologne, Kerpenerstrasse. 62, 50937 Cologne, Germany

e-mail: hakan.alakus@uk-koeln.de 